\title{
Effect of Different Polymerization Methods on the Cytotoxicity of Dental Composites
}

\author{
Nilufer Celebi Beriat ${ }^{a}$ \\ Ahmet Atila Ertan ${ }^{b}$ \\ Senay Canayb \\ Aylin Gurpinarc \\ Mehmet Ali Onur
}

\section{ABSTRACT}

Objectives: The aim of this study was to compare the cytotoxic effects of various dental composites polymerized with two different curing units.

Methods: Disc-shaped test samples of composites Filtek Z250, Filtek A110, Filtek P60, Filtek Supreme, and SDI Rok were polymerized using one quartz tungsten halogen (QTH) and one light emitting diode (LED) light curing unit (LCU), namely Optilux 501 (QTH) and Elipar Freelight 2 (LED). L-929 mouse fibroblast cultures $\left(3 \times 10^{4} \mathrm{cells} / \mathrm{ml}\right)$ were incubated with the samples in 96 well culture plates for evaluation after $8,24,48,72 \mathrm{~h}$. At the end of each period, the cells were counted and examined under a light microscope, and a 3-[4,5-dimethylthiazol-2-yl]-2,5-diphenyltetrazolium bromide (MTT) assay was performed. The degree of cytotoxicity for each sample was determined according to the reference value represented by the cells in a control group (a culture without sample).

Results: A significant 3 factor interaction occurred among LCUs, composites, and time factors $(P<.005)$. In general, the test materials cured with the LED LCU demonstrated higher cell survival rates when compared with those cured with halogen LCUs.

Conclusions: This study shows that polymerization of dental composites with a light emitting diode LCU positively influences the L-929 mouse fibroblast cell viability. (Eur J Dent 2010;4:287-292)

Key words: Cytotoxicity; Dental composite; Light curing units.

\section{INTRODUCTION}

Light curing resin composites have been used with increasing frequency as restorative materials and an established alternative to dental amalgam for their aesthetic merits and easy handling.

\footnotetext{
a Hacettepe University, School of Dental Technology, Ankara, Turkey.

b Hacettepe University, Faculty of Dentistry, Department of Prosthodontics, Ankara, Turkey. Hacettepe University, Faculty of Science, Department of Biology, Ankara, Turkey.

- Corresponding author: Nilufer Celebi Beriat, Hacettepe University, School of Dental Technology, 06100, Sihhiye, Ankara, Turkey.

E-mail: nberiatahotmail.com
}

In permanent teeth, dental resin composites are the most important tooth colored filling materials, and in the primary dentition, with its specific conditions, compomers also play an important role. However, the primary problem with composite resin is polymerization shrinkage. Second, insufficient polymerization leads to high residual monomers being released in the oral environment. ${ }^{1}$ The majority of unreacted components may be released during the first few days. Residual monomers may enter the human body via the skin, oral and gastro intestinal mucosa, dentin, and pulp. ${ }^{2}$ Their physical properties are constantly im- 
proved by manufacturers, and their composition is chemically complex since they contain a great variety of different monomers and additives. The liberation of components from composites may influence the biocompatibility as well as the mechanical properties of the restorations. Generally, they consist of an organic matrix, reinforcing fillers (mainly inorganic), and a silane coupling agent, which connects the inorganic fillers. The organic polymerized matrix is mostly responsible for undesirable effects. In vitro studies show that the polymerization reaction is never complete and that adverse reactions are due to the release of nonpolymerized monomers, such as TEGDMA or Bis-GMA and UDMA. ${ }^{3,4}$ In most studies, co-monomer TEGDMA has been identified as the main compound released from polymerized resin composites into aqueous media. However, small quantities of monomers Bis-GMA and UDMA and other co-monomers, as well as additives, may also be released. Co-monomer TEGDMA is cytotoxic and inhibits cell growth. ${ }^{3}$ In the first hours after initial polymerization, unreacted monomers and/or additives are released by solvents or polymer degradation. Therefore, inadequate polymerization is the crucial factor in the release of unreacted monomers. According to Ferracane, approximately $15 \%$ to $50 \%$ of the methacrylic groups are left unreacted following initial polymerization. ${ }^{5}$ Although the percentage of unreacted monomers after initial polymerization is lower in new materials, there is still no total conversion during polymerization. The cytotoxic effect on the pulp cells of these unreacted monomers is also dependent on dentin permeability and residual dentin thickness. ${ }^{6}$ However, these parameters are not directly under the operator's control.

In all methanol extracts from various resin composites, photoinitiator camphoroquinone (CQ) was found. Furthermore, extracts from hybrid resin composites contain photoinitiating substances benzyl (BL) and dimethoxybenzoin (DMBZ). In the extract of one composite, triphenylphosphan (TPP) and triphenylstibane (TPsb) were detected. These substances were used as catalysts. , $^{7}$

The success of polymerization depends on the thickness of the filling material, the wavelength of the excitation light, the power density, and the time of irradiation. Tuning between excitation wavelength and the photoinitiator system has a deci- sive effect on the degree of polymerization. There are various types of light curing units (LCUs) in the dental market, such as quartz tungsten halogen (QTH) and light emitting diode (LED) curing units. QTH units have been used to polymerize composite resin, but the drawback of the halogen unit is a decline in irradiance over time due to aging lamps and filters. A recent alternative to QTH, LED curing units are increasingly used in dental practice. The LED has the advantages of extended of lifetimes of over $10000 \mathrm{~h}$, little degradation of light output over time, and resistance to shock, overheating, and vibration. ${ }^{2}$ The spectral output of LEDs consists of the absorption peak of CQ (400-500 nm, peak at $470 \mathrm{~nm}$ ), the most used photoinitiator in resin composites. Comparative studies demonstrated that the type of LCU is an important factor for both curing efficiency and generated heat.8,9 However, few studies have investigated the cytotoxicity of composites with different curing methods. The determination of the possibly toxic effect of composites is a matter of interest. In view of the great variety of LCUs and filling materials currently in use, the question is which combinations cause the least toxic effects. The present study aimed to explore, in an in vitro model, the possible cytotoxicity of various composite-LCU combinations.

\section{MATERIALS AND METHODS}

Sample preparation

The A3 shades of composites Filtek P60, Filtek A110, Filtek Supreme, Filtek Z250 (3M ESPE, St. Paul, MN, USA) and SDI Rok (SDI Ltd., Victoria, Australia) were evaluated in this study. The composition of each material is detailed in Table 1. For each material, disc-shaped samples $12 \mathrm{~mm}$ diameter and $2 \mathrm{~mm}$ in thickness) were prepared using Teflon molds. These molds were placed on flat glass plates on top of Mylar strips (Moyco Union Broach, York, USA) and then filled in bulk with composites. The composites were then covered with an acetate strip and gently pressed with another flat glass plate. Next, excess material was removed with a scalpel (Otto Rüttgers $\mathrm{GmBH}$, Solingen, Germanyl. The top glass plate was removed to polymerize the samples. The samples were polymerized and randomly divided into two groups ( $n=6 /$ group) according to the LCU: 1) QTH/40secs (Optilux 501, Kerr, Orange, CA) and 2) LED/20secs (Elipar Freelight II, 3M/ESPE, Seefeld, 
Germany). The LCUs were all used in standard mode (continuous, constant light intensity). Before photoactivation, the irradiance of both curing units was confirmed with QTH and LED radiometers (Kerr/Demetron, Orange, CA, USA). The output spectrum for the LED was concentrated within the 425-500 $\mathrm{nm}$ wavelength range, while that of the Optilux 501 is considerably wider (375-520 nm). However, the spectral flux of the LED was much higher at $425-475 \mathrm{~nm}$, the effective range of $C Q$ the photo-initiator for both resins (Figure 1).

\section{Cell proliferation}

The cells used for the experiment were L929 mouse fibroblasts. The cells were grown as monolayer cultures in 25T-flasks (Corning, NY, USA) in Dulbecco's Modified Eagle's Medium/F12 (DMEM/ F12) (Sigma Chemical Co. St. Louis, MO, USA) containing 10\% fetal calf serum (Biochrom AG, Germanyl in a humidified atmosphere of $95 \%$ air and $5 \% \mathrm{CO}_{2}$ at $37^{\circ} \mathrm{C}$. After the $2^{\text {nd }}$ passage, the $\mathrm{L} 929 \mathrm{fi}-$ broblastic cell line was plated in 96-well culture plates at an initial density of 30,000 cells $/ \mathrm{ml}$ with test materials and incubated in the same medium in a humidified atmosphere of $95 \%$ air and $5 \% \mathrm{CO}_{2}$ at $37^{\circ} \mathrm{C}$. One sample was used for each well. Cells cultured without the test materials were used as a control group. L929 cells were incubated for $72 \mathrm{~h}$ at $37^{\circ} \mathrm{C}$. In order to assay the cell proliferation, the cell number was counted at $8 \mathrm{~h}, 24 \mathrm{~h}, 48 \mathrm{~h}$, and $72 \mathrm{~h}$. At the end of each period, the culture medium was removed, and the cells were collected from the surface of the culture dish using $0.25 \%$ trypsinEDTA (Sigma Chemical Co., St. Louis, MO, USA). L929 cells were counted with trypan blue (Sigma Chemical Co., St. Louis, MO, USA) and examined under a light microscope (Olympus, Kyoto, Germanyl. Each experiment was repeated 3 times for each test material and control group.

\section{Cell viability assay}

The L929 fibroblastic cell line was plated in 96well culture plates at an initial density of 30,000 cells $/ \mathrm{ml}$ with test materials and incubated in Dulbecco's Modified Eagle's Medium/F12 (DMEM/ F12) (Sigma Chemical Co., St. Louis, MO, USA) containing $10 \%$ fetal calf serum (Biochrom AG, Germany) in a humidified atmosphere of $95 \%$ air and $5 \% \mathrm{CO}_{2}$ at $37^{\circ} \mathrm{C}$. Cells cultured without the test materials were used as a control group. L929 cells were incubated for 7 days at $37^{\circ} \mathrm{C}$. At $8 \mathrm{~h}, 24 \mathrm{~h}, 48 \mathrm{~h}$, and $72 \mathrm{~h}$, the culture medium was removed from the wells, and $100 \mu \mathrm{l}$ RPMI-1640-without fenol red (Sigma Chemical Co. St. Louis, MO, USA) containing $12.5 \mu \mathrm{l}$ MTT (tetrazolium salt 3-[4,5-dimethylthiazol-2-yl]-2,5-diphnyltetrazolium bromide) was added to each well. Culture plates were covered with aluminum foil (Mavipak, Ankara, Turkey), and cells were incubated in the dark for $4 \mathrm{~h}$. After the $4 \mathrm{~h}$ incubation, the MTT solution was removed from the wells, and $100 \mu$ isopropyl alcohol was added. The absorbance at $570 \mathrm{~nm}$ was measured using an Ultraviolet visible spectrophotometer (Shimadzu, Tokyo, Japan). The cell viability was calculated according to the following formula:

Cell viability (\%): 100x $\frac{\text { Optical densities of test groups }}{\text { Optical densities of control groups }}$

The data were analyzed with SPSS 10.0 statistics program for Windows. The mean, median, minimum, maximum, and standard deviations were calculated. Significance was tested with Kruskall-Wallis, and for multiple comparisons, the Mann Whitney $U$ with Bonferroni correction test was applied.

\section{RESULTS}

The method of polymerization affected the cell viability of the materials significantly $(P<.05)$. However, at the $1^{\text {st }}$ time interval $(4 \mathrm{~h})$, the difference was not significant (Figure 2). The materials that were polymerized with LED curing units became less cytotoxic overall. At the $1^{\text {st }}$ time interval, there was no statistically significant difference among the materials that were polymerized with QTH devices (Figure 3). This was also true for the group that was polymerized with LED curing devices. At the $2^{\text {nd }}$ time interval $(24 \mathrm{~h})$, there was a statistically significant difference among the materials in the QTH curing group. Filtek P60 had the least cytotoxicity, and Filtek A110, the highest. For the LED curing group, there was no statistically significant difference among materials. At the $3^{\text {rd }}$ time interval (48h), there was a statistically significant difference among materials in the LED group. Filtek Z250 had the least cytotoxicity, and SDI ROK and Filtek Supreme, the highest. There was also a significant difference between the QTH and LED groups at the $3^{\text {rd }}$ time interval. The LED curing group had the least cytotoxicity. In the QTH 
group, there was a statistically significant difference among materials at the $3^{\text {rd }}$ time interval. Filtek Z250 had the least cytotoxicity, and Filtek Supreme and Filtek P60, the highest. At the $4^{\text {th }}$ time interval (72h), there was a statistically significant difference between the polymerization methods. The LED curing method had the least cytotoxicity. In the LED group, Filtek A110 demonstrated the least cytotoxicity, and Filtek Supreme, the highest. In the QTH group, Filtek Supreme had the least cytotoxicity, and Filtek A110 the highest.

\section{DISCUSSION}

The biocompatibility of dental materials has been investigated through different methods. ${ }^{10}$ In the present study, the effect of resin composites cured with LED or QTH on L-929 fibroblasts was investigated with MTT assay. The MTT assay is a good indicator of cell viability. ${ }^{11}$ This assay is based on the reduction of the MTT by those cells that remain viable after exposure and incubation with a

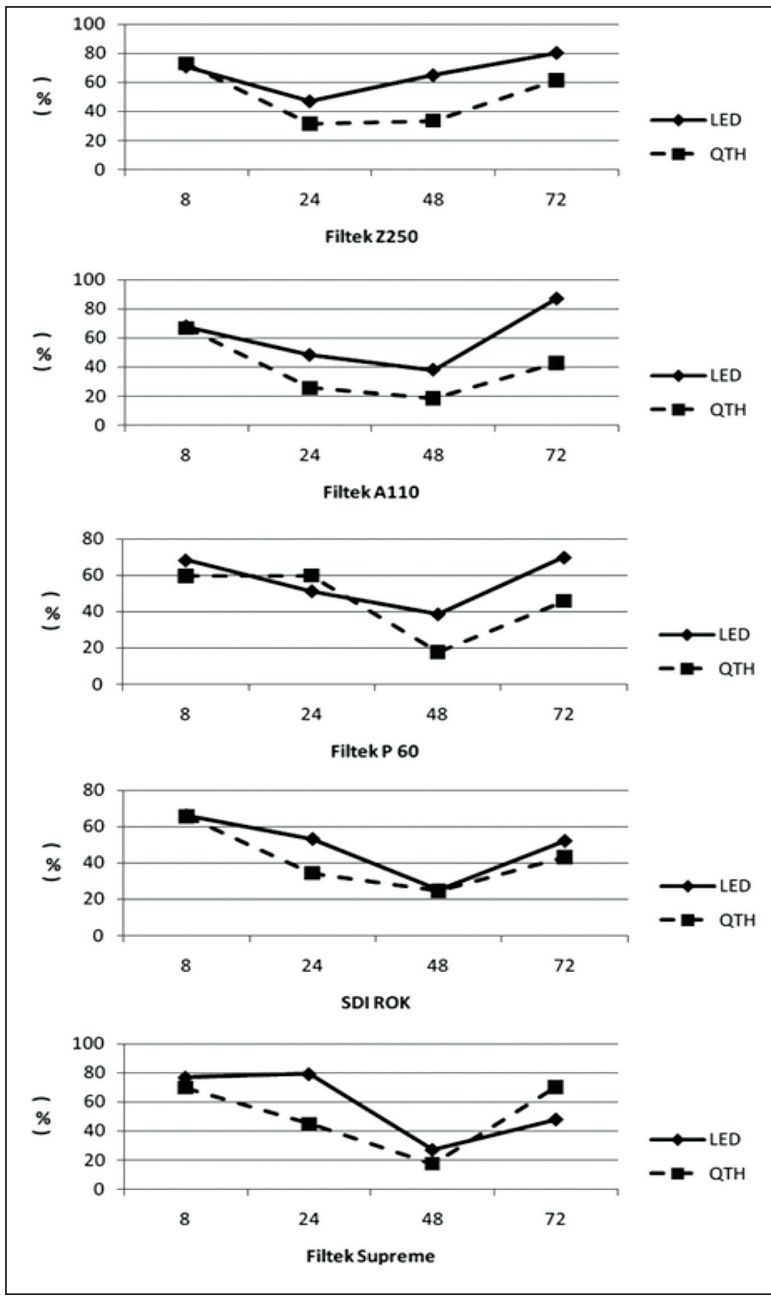

Figure 1. Cell viability of the samples polymerized by LED and QTH light curing units. test chemical or device. Mitochondrial dehydrogenases at the cytochrome b and cytochrome $c$ sites of viable cells convert the yellow water soluble form of the salt to an insoluble, intracellular purple formazon metabolite. A formazon solubilized by extraction with alcohol or DMSO can be quantified spectrophotometrically with results related to the proportion of viable cells. ${ }^{12}$ In this study, cytotoxicity was evaluated through direct contact between the composite specimen and the cells. In the literature, there are a variety of different in vitro test models for cytotoxicity, including direct contact tests and indirect contact and extract tests. ${ }^{13}$ In this study, the direct method was preferred because it allowed for a more legitimate comparison between aging intervals, as each set of specimens was statistically independent. However, the important point is to be aware that these strategies may or may not give the same results depending on the materials and measurement times.

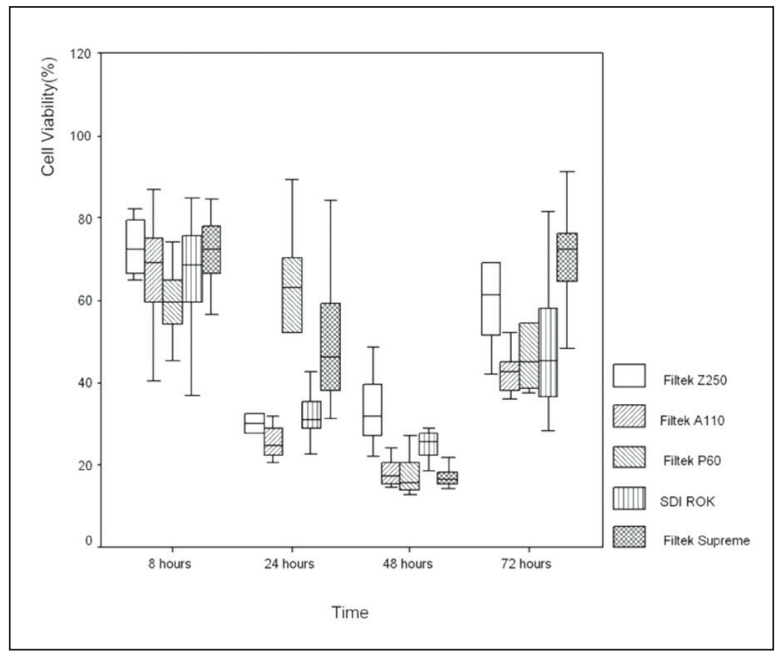

Figure 2. Cell viability of the samples polymerized by LED.

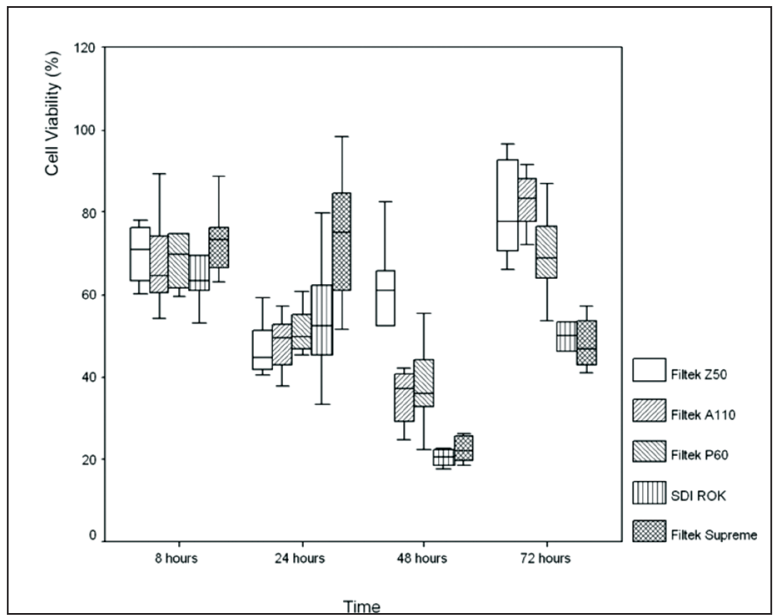

Figure 3. Cell viability of the samples polymerized by QTH. 
LCUs affect the degree of conversion depending on the photoinitiator in the resin composite. In literature, there were studies related to the polymerization methods on the cytotoxicity of dental composites suggesting that there were no statistically significant differences between polymerization methods. ${ }^{14}$ Nevertheless, the results of this study revealed that using LED curing units has a positive effect on cytotoxicity. Although the outcome of this study is in accordance with Sigusch et al, ${ }^{15}$ other studies indicate that LED curing units may not produce more biocompatible photo-po- lymerized materials when compared to QTH curing units. ${ }^{16}$

$\mathrm{CQ}$ is an $\alpha$-dicarbonyl absorbing at $468 \mathrm{~nm}$ that is compatible both with LED and QTH curing units. However other photoinitiators, such as phenylpropanedione and diphenyl phosphinoxid, have different absorption spectra; therefore, polymerizing with LED curing units is difficult. ${ }^{17}$ To avoid polymerization failure when using new resin composites, one must follow the manufacturer's instructions with respect to the choice of curing unit.

Table 1. Materials, manufacturers, and approximate resin composition (According to manufacturers' information).

\begin{tabular}{|c|c|c|c|c|}
\hline Material & Lot no & Manufacturer & Approximate re & mposition \\
\hline \multirow{6}{*}{ Filtek Z250 } & \multirow{6}{*}{$2 N M$} & \multirow{6}{*}{ 3M ESPE, St. Paul, MN, USA } & $\begin{array}{c}\text { Fillers (Silane Treated } \\
\text { Ceramics) }\end{array}$ & $\% 75-80$ \\
\hline & & & Bis-EMA & $\% 5-10$ \\
\hline & & & Diurethane Dimethacrylate & $\% 5-10$ \\
\hline & & & Bis-GMA & $\% 1-10$ \\
\hline & & & Tegdma & $<\% 5$ \\
\hline & & & Water & $<\% 2$ \\
\hline \multirow{5}{*}{ Filtek A110 } & \multirow{5}{*}{ OAJ } & \multirow{5}{*}{ 3M ESPE, St. Paul, MN, USA } & Fillers(Silane Treated Silica) & $\% 55-65$ \\
\hline & & & TEGDMA & $\% 15-25$ \\
\hline & & & Bis-GMA & $\% 15-25$ \\
\hline & & & $\begin{array}{l}\text { Methacyloxypropyl Me- } \\
\text { thoxysilane Oligomer }\end{array}$ & $<\% 2$ \\
\hline & & & Benzoyl Peroxide & $<\% 0,3$ \\
\hline \multirow{8}{*}{ Filtek P60 } & \multirow{8}{*}{$1 \mathrm{KE}$} & \multirow{8}{*}{ 3M ESPE, St. Paul, MN, USA } & Fillers & $\% 75-85$ \\
\hline & & & $\begin{array}{c}\text { Bisphenol A Polyethylene } \\
\text { Glycol }\end{array}$ & $\% 5-10$ \\
\hline & & & Diether Dimethacrylate & \\
\hline & & & $\begin{array}{l}\text { Trimethyl- Diazahexadec- } \\
\text { anediyl }\end{array}$ & $\% 5-10$ \\
\hline & & & Bismethacrylate & \\
\hline & & & $\begin{array}{c}\text { Methylethylidene Phenyl- } \\
\text { eneoxy } \\
\text { Bismethacrylate }\end{array}$ & $\% 1-10$ \\
\hline & & & $\begin{array}{l}\text { Ethylenedioxydiethyl Di- } \\
\text { methacrylate }\end{array}$ & $<\% 5$ \\
\hline & & & Water & $<\% 2$ \\
\hline \multirow{6}{*}{ Filtek Supreme XT } & \multirow{6}{*}{$5 A M$} & \multirow{6}{*}{ 3M ESPE, St. Paul, MN, USA } & $\begin{array}{l}\text { Fillers (Silane Treated } \\
\text { Ceramic And Silica) }\end{array}$ & $\begin{array}{c}\% 65-75 \text { (Ceramic) } \\
\% 5-10 \text { (Silica) }\end{array}$ \\
\hline & & & Bis-EMA & $\% 5-15$ \\
\hline & & & Diurethane Dimethacrylate & $\% 5-15$ \\
\hline & & & Bis-GMA & $\% 1-10$ \\
\hline & & & TEGDMA & $<\% 5$ \\
\hline & & & Water & $<\% 2$ \\
\hline \multirow[b]{2}{*}{ ROK } & \multirow[b]{2}{*}{502102} & \multirow[b]{2}{*}{ SDI, Australia } & Acrylic Monomer & $\% 18-40$ \\
\hline & & & $\begin{array}{c}\text { Balance İngredient (Non- } \\
\text { Hazardous) }\end{array}$ & $\% 60-82$ \\
\hline
\end{tabular}


In vitro studies evaluating the cytotoxicity of dental composites have indicated moderate to severe cytotoxic effects. ${ }^{11,14,18}$ In this study, all materials that were tested were severely cytotoxic probably because this test was conducted over a short period. At early intervals, studies indicate that resin containing materials are more cytotoxic than at later intervals. In the literature, the results of in vitro cytotoxicity studies vary according to the material tested, but they are dependent in terms of the cells used for testing. ${ }^{19}$

In this study, there was no interpretable pattern of cytotoxicity among the restorative materials and time intervals. However, samples polymerized with LED curing units demonstrated less cytotoxicity overall.

\section{CONCLUSIONS}

Within the limitations of this study, it can be concluded that polymerization of dental composites with a LED LCU positively influences L-929 mouse fibroblast cell viability.

\section{REFERENCES}

1. Davidson CL,Feilzer AJ. Polymerization shrinkage and polymerization shrinkage stress in polymer-based restoratives. J Dent 1997;25:435-440.

2. Moon HJ, Lee YK, Lim BS,Kim CW. Effects of various light curing methods on the leachability of uncured substances and hardness of a composite resin. J Oral Rehabil 2004;31:258-264.

3. Engelmann J, Leyhausen G, Leibfritz D,Geurtsen W. Metabolic effects of dental resin components in vitro detected by NMR spectroscopy. J Dent Res 2001;80:869-875.

4. Geurtsen W. Substances released from dental resin composites and glass ionomer cements. Eur J Oral Sci 1998; 106:687-695.

5. Ferracane JL,Greener EH. Fourier transform infrared analysis of degree of polymerization in unfilled resins-methods comparison. J Dent Res 1984;63:1093-1095.

6. Bouillaguet S, Virgillito M, Wataha J, Ciucchi B,Holz J. The influence of dentine permeability on cytotoxicity of four dentine bonding systems, in vitro. $J$ Oral Rehabil 1998;25:45-51.

7. Heil J, Reifferscheid G, Waldmann P, Leyhausen G,Geurtsen W. Genotoxicity of dental materials. Mutat Res 1996;368:181-194.
8. Lindberg A, Peutzfeldt A,van Dijken JW. Effect of power density of curing unit, exposure duration, and light guide distance on composite depth of cure. Clin Oral Investig 2005;9:71-76.

9. Uhl A, Mills RW, Jandt KD. Photoinitiator dependent composite depth of cure and Knoop hardness with halogen and LED light curing units. Biomaterials 2003;24:1787-1795.

10. Murray PE, Garcia Godoy C,Garcia Godoy F. How is the biocompatibilty of dental biomaterials evaluated? Med Oral Patol Oral Cir Bucal 2007;12:E258-266.

11. Bean TA, Zhuang WC, Tong PY, Eick JD, Chappelow CC,Yourtee DM. Comparison of tetrazolium colorimetric and $51 \mathrm{Cr}$ release assays for cytotoxicity determination of dental biomaterials. Dent Mater 1995;11:327-331.

12. Cao T, Saw TY, Heng BC, Liu H, Yap AU,Ng ML. Comparison of different test models for the assessment of cytotoxicity of composite resins. J Appl Toxicol 2005;25:101-108.

13. Nalcaci A, Oztan MD,Yilmaz S. Cytotoxicity of composite resins polymerized with different curing methods. Int Endod $J$ 2004;37:151-156.

14. Sigusch BW, Volpel A, Braun I, Uhl A,Jandt KD. Influence of different light curing units on the cytotoxicity of various dental composites. Dent Mater 2007;23:1342-1348.

15. Tseng WY, Huang CH, Chen RS, Lee MS, Chen YJ, Rueggeberg FA, et al. Monomer conversion and cytotoxicity of dental composites irradiated with different modes of photoactivated curing. J Biomed Mater Res B Appl Biomater 2007;83:85-90.

16. Uhl A, Sigusch BW, Jandt KD. Second generation LEDs for the polymerization of oral biomaterials. Dent Mater 2004;20:80-87.

17. Goldberg M. In vitro and in vivo studies on the toxicity of dental resin components: a review. Clin Oral Investig 2008;12:1-8.

18. Quinlan CA, Zisterer DM, Tipton KF,O'Sullivan MI. In vitro cytotoxicity of a composite resin and compomer. Int Endod $J$ 2002;35:47-55.

19. Geurtsen W, Spahl W,Leyhausen G. Residual monomer/ additive release and variability in cytotoxicity of light-curing glass-ionomer cements and compomers. J Dent Res 1998;77:2012-2019. 